\title{
LOS DESPLAZAMIENTOS HUMANOS FORZADOS RECIENTES EN EL CAUCA (COLOMBIA): CARACTERÍSTICAS E IMPACTOS SOCIALES Y ESPACIALES ${ }^{1}$
}

\author{
Ricardo Manuel Luque Revuelto \\ Departamento de Geografía y Ciencias del Territorio. Universidad de Córdoba (España) \\ chllurer@uco.es
}

\section{RESUMEN}

Este artículo revela la situación actual del desplazamiento forzado en el departamento de Cauca (Colombia). Parte de un análisis previo de la población y el territorio caucano. Seguidamente se esbozan las características de dichos desplazamientos, atendiendo a los actores, el destino y las causas que provocan estos movimientos de población. Las consecuencias son devastadoras, no solo en el ámbito sociodemográfico, sino que además inducen profundas secuelas territoriales en los espacios agrarios, urbanos o en los espacios naturales y protegidos. A modo de conclusión se exploran las posibles soluciones al conflicto y el papel de los actores implicados en el mismo.

Palabras clave: Desplazamiento forzado; Pueblos indígenas; Impactos ambientales; Conflicto socioterritorial; Cauca (Colombia).

\section{ABSTRACT \\ Recent forced human displacement in Cauca (Colombia): characteristics and social and spatial impacts}

This article explains the current situation with regard to forced displacement in the department of Cauca (Colombia). It begins with a preliminary analysis of the population of Cauca and its territory, followed by an outline of the main characteristics of these movements, focusing on the agents, destination and causes of these population movements. The consequences are devastating, not only in the demographic field, but they also entail profound consequences for agricultural land, urban areas or natural and protected areas. To conclude, the possible solutions to the conflict and the role of the agents involved in it are also analysed.

Keywords: Forced displacement; Indigenous peoples; Environmental impacts; Territorial social conflict; Cauca (Colombia).

Colombia se encuentra en estos momentos en una encrucijada en la que debe decidir su futuro inmediato. Los diálogos de paz entre el actual gobierno del presidente Juan Manuel Santos y las Fuerzas Armadas Revolucionarias de Colombia (FARC), también conocidos como Proceso de Paz en Colombia, se desarrollan en La Habana. El principal objetivo de las negociaciones consiste en la búsqueda de un acuerdo general para la terminación del conflicto y la construcción de una paz estable y duradera.

El conflicto armado en Colombia se inicio a finales de los años cincuenta y ha ocasionado más de doscientas mil muertes, seis millones de damnificados y más de cinco millones de desplazados. En el presente y 30 años después de la Declaración de Cartagena sobre los Refugiados (1984) la situación política y regional se ha reconfigurado en las democracias latinoamericanas por la superación del marco de la Guerra Fría y

\footnotetext{
1 En base a los resultados del Proyecto de Investigación que con el mismo título ha sido financiado en el marco del Programa Propio de Internalización y Cooperación Internacional de la Universidad de Córdoba en el año 2014 en la modalidad 3: Cooperación al Desarrollo de la Universidad de Córdoba (España) y cuyo investigador principal es el autor del presente artículo.
} 
las dictaduras militares, si bien el número de refugiados y desplazados por causa de la violencia no cesa, siendo precaria todavía la construcción de la paz y del Estado de derecho².

Figura 1. Departamento del Cauca

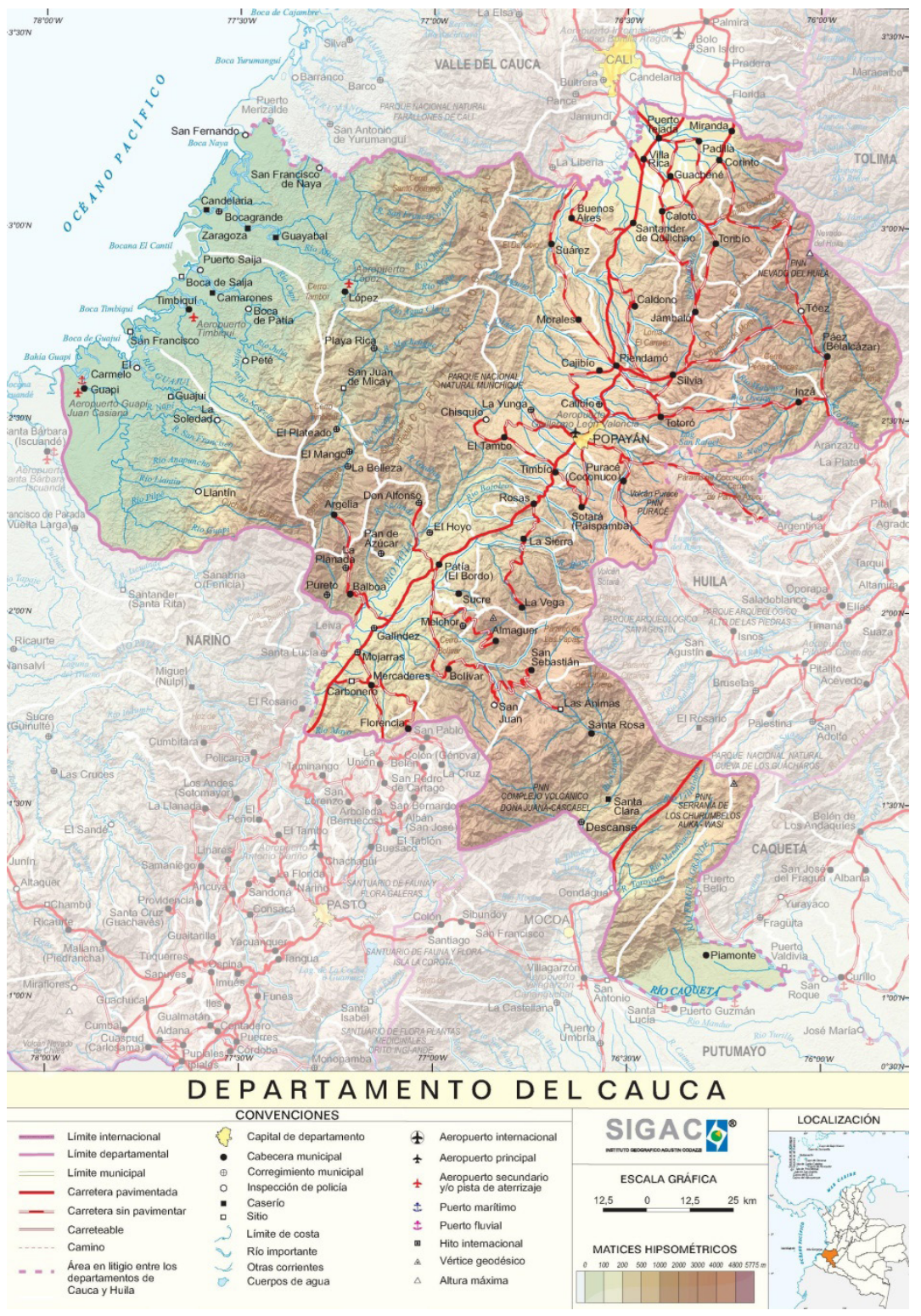

Fuente: Instituto Geográfico Agustín Codazzi (2012a). Mapa físico-político departamental 2012.

El departamento del Cauca constituye un crisol de todos los conflictos y en donde las cifras de víctimas por la violencia armada, e incluso por los desastres naturales, alcanza cifras elevadísimas. Esta situación se deriva en gran parte de los intereses que confluyen en el departamento en materia geoestratégica y ambiental, de manera que lo convierten en una pieza clave dentro de la coyuntura nacional. Es así como esta situación ha propiciado importantes modificaciones demográficas y territoriales. Las primeras afectan a los movimientos espaciales de diferentes etnias y comunidades campesinas, las segundas se han traducido en un notable deterioro del medio ambiente y en una modificación de la estructura de la propiedad de la tierra, de la explotación y los cultivos, así como de los espacios urbanos que reciben a la población desplazada por la violencia. 


\section{POBLACIÓN Y TERRITORIO}

El Cauca, con sus $29.308 \mathrm{~km}^{2}$ de superficie, es un extenso departamento colombiano que pertenece al sistema andino. Situado en un lugar estratégico, es nudo de comunicaciones en el que se bifurcan las cordilleras Central y Occidental, y en donde nacen los ríos Magdalena, Cauca, Caquetá y Patía. En él se pueden diferenciar siete unidades morfológicas: la llanura del Pacífico, la cordillera Occidental, la cordillera Central, el altiplano de Popayán, el Macizo Colombiano, el Valle del Patía y el sector de la cuenca del Amazonas conocido como la "bota Caucana".

Cauca es un departamento que depende de la agricultura y la minería. Se cultiva principalmente caña de azúcar y otros productos como maíz, plátano, café, yuca, trigo, arroz, fríjol, tabaco, cacao y papa. La actividad minera, con importantes yacimientos de oro, plata, platino y carbón, es una actividad en auge que está generando, no pocos conflictos medioambientales, sino también étnicos y sociales. Su IDH $(0,782)$ (Programa de las Naciones Unidas para el Desarrollo [PNUD], 2011) se encuentra por debajo de la media nacional $(0,840)$ siendo el octavo departamento por la cola de los 33 existentes.

Actualmente Cauca tiene 1.366.984 habitantes de los 47.661 .787 con que cuenta el país (Departamento Administrativo Nacional de Estadística [DANE], a 30 de julio de 2014), lo que arroja una densidad media de población de 46,64 hab/ $\mathrm{km}^{2}$, muy próxima a la media nacional $\left(41,74 \mathrm{hab} / \mathrm{km}^{2}\right)$. El Cauca está constituido por una gran variedad étnica. Los blancos y mestizos ocupan la zona central del departamento y la capital, suponen el 56\%. Hacia el oriente, en Tierradentro, se ubican las comunidades indígenas que constituyen el 21\%. Finalmente, en la costa del Pacífico, viven los descendientes de africanos que conforman el 23\% de la población. En la cabecera departamental residen 541.406 habitantes y 825.578 repartidos en el resto de municipios. La mayor parte de la población se asienta en el valle del Río Cauca, entre las cordilleras Central y Occidental. Popayán, la capital, situada en este valle, concentra más de la mitad del poblamiento caucano y, dentro del departamento, solo la ciudad de Santander de Quilichao supera los cincuenta mil habitantes, el resto se reparte en pequeños núcleos de población y caseríos repartidos por los 38 municipios y 99 corregimientos que comprenden el departamento.

Figura 2. Pirámide de población de Cauca

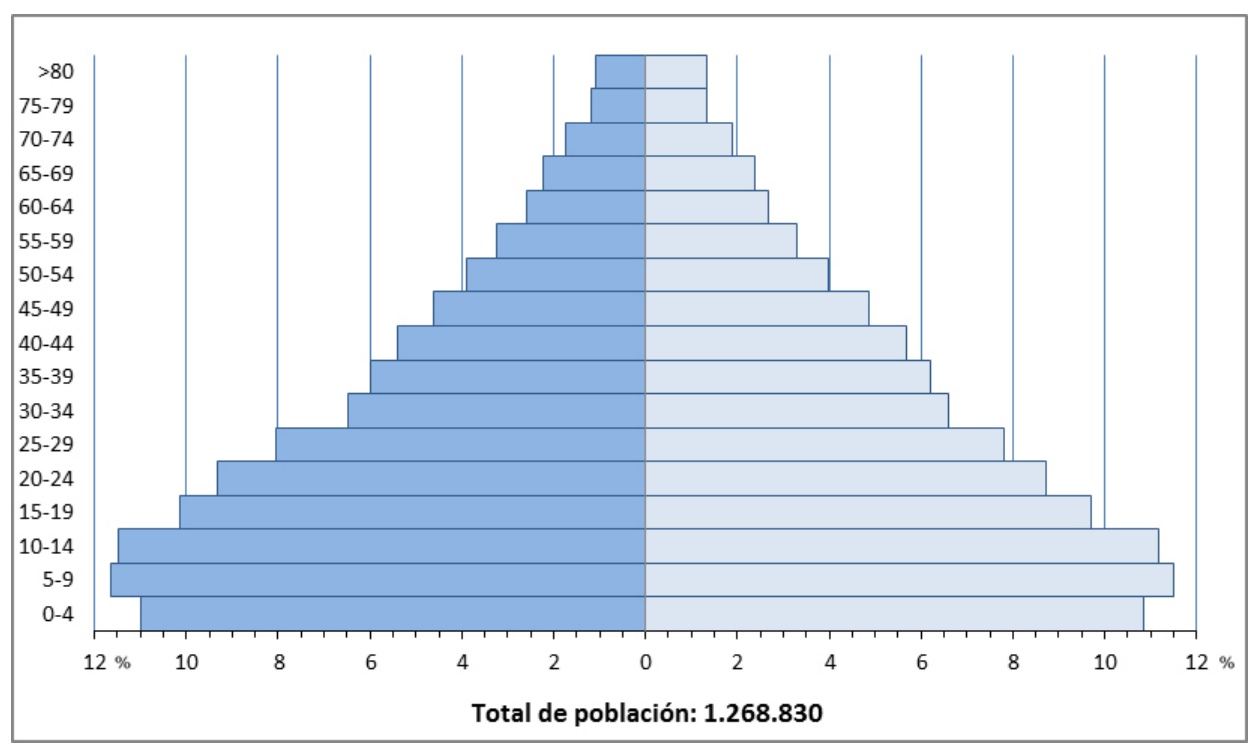

Fuente: DANE. Censo General 2005.

La pirámide de edades (Figura 2) nos muestra una población joven y que ha experimentado en fechas recientes una progresiva reducción de su base debido al descenso de las tasas de natalidad, debilitadas no solo por las dificultades económicas sino por la magnitud de los desplazamientos forzados que han separado, destruido y precarizado a miles de familias. De ello da fe la tasa bruta de natalidad, que fue del 11,9 por mil frente al 19,8 por mil de la media nacional en el periodo 2005-2010. La tasa de fecundidad en el Cauca, mucho más indicativa, según el DANE, descendió del 86,70 por mil, en el quinquenio 20052010, al 83,00 por mil en el quinquenio actual. Y también lo hizo la tasa global de fecundidad, pasando de 
2,77 hijos por mujer a 2,66 hijos, para los mismos quinquenios. Cifras estas que de nuevo se desacoplan de las medias nacionales.

La consideración de la mortalidad y de los factores que la rodean requiere un análisis más pormenorizado habida cuenta de las particulares circunstancias de inseguridad y riesgo humanitario que aquejan a este departamento colombiano. Así, todos los indicadores muestran valores considerablemente distanciados de las medias nacionales y en algunos casos, el departamento, viene a engrosar la cola de la estadística colombiana. En efecto, la tasa bruta de mortalidad, que apenas opera mejoría con respecto al quinquenio 2005-2010, se estima en 2010-2015 en 6,72 por mil, un punto por encima de la nacional y solo superada por los departamentos de Boyacá, Caldas y Quindío. La esperanza de vida al nacer para el quinquenio considerado es de 69,59 años para los varones y de 75,30 para las mujeres. De nuevo por debajo de la media nacional, que se eleva en tres años para los varones y las mujeres, y con dígitos inferiores tan solo en Chocó y Caquetá. La mortalidad infantil viene aún a distanciarse más: con un 43,60 por mil frente al 17,10 nacional. Valores superiores tan solo los alcanza Chocó y Arauca (DANE, 2007).

Figura 3. Mapa de víctimas de violencia armada y desastres naturales. 2008-2015

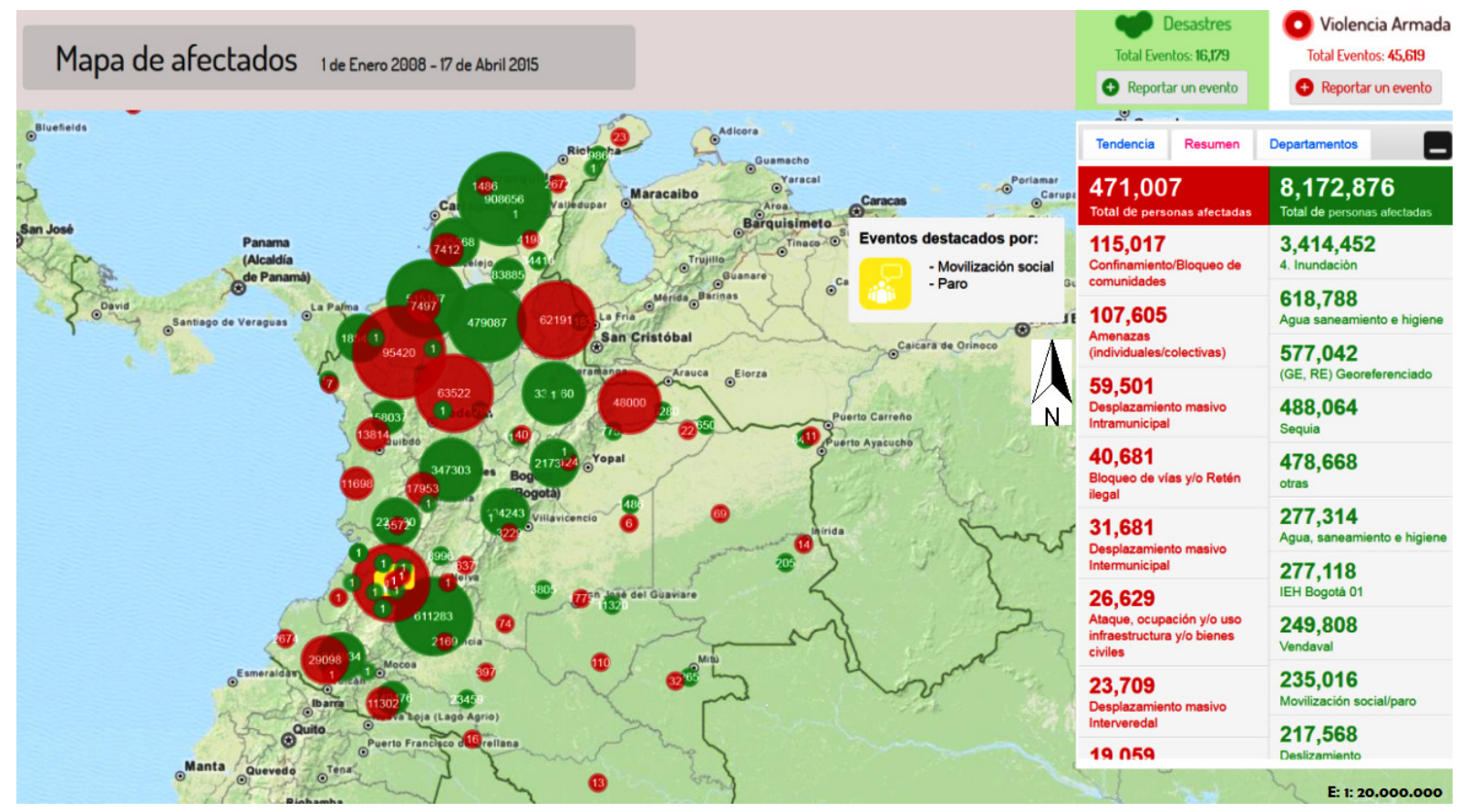

Fuente: Office for the Coordination of Humanitarian Affairs [OCHA]. MONITOR Sala de Situación Humanitaria.

Puesto que los indicadores convencionales de dicho movimiento natural quedan superados es preciso valorar otras circunstancias: así, el número total de afectados por desastres naturales en Colombia contabiliza la cifra de 8.172.876 personas entre 2008 y los primeros meses de 2015 (figura 3). Inundaciones, problemas de saneamiento del agua, deslizamientos de tierras, vendavales, etc. son los principales motivos. Las víctimas de la violencia armada se aproximan ya al medio millón de personas: confinamiento o bloqueo de comunidades, amenazas, desplazamientos, víctimas de combates, masacres, minas, etc. son los causantes.

En Cauca el total de personas afectadas entre dichas fechas alcanza a 263.049 y el de víctimas de la violencia armada a 46.490. Inundaciones (101.149), deslizamientos, (59.378), avalanchas (24.662), sequias $(23.463)$, incendios $(20,494)$ y vendavales $(18,860)$ han ocasionado miles de damnificados. Las cifras recogidas de la violencia resultan estremecedoras: en 2012 fueron asesinados 316 hombres y $27 \mathrm{mu}$ jeres $^{3}$. La tasa de homicidios, de por si elevada en Colombia, (32,33 por mil), en Cauca alcanza el doble $(61,42$ por mil). Los eventos bélicos, que se han reducido en bastantes de los departamentos, en Cauca se

3 Sidih, OCHA, MONITOR Sala de Situación Humanitaria. 
mantienen y, no solo ocasionan víctimas mortales, sino heridos, mutilados y, sobre todo, desplazamientos humanos. En la tabla 1 figura el número de eventos bélicos y su distribución municipal. De ella se puede colegir que el conflicto permanece armado continua vivo en Cauca y que afecta a buena parte de su territorio. Aún en aquellos municipios en los que ha descendido el número de afectados por los enfrentamientos militares se siguen registrando damnificados por efectos de las minas antipersonal. Así en el periodo comprendido entre 2001 y 2014 son 504 personas las que han sido mutiladas o han fallecido por esta causa ${ }^{4}$. Al margen de la estadística, o con datos menos fiables, son destacables los casos de torturas, desaparecidos y secuestros, de los que se viene haciendo eco la prensa de forma regular.

Tabla 1. Número de eventos bélicos en Cauca (2009-2014)

\begin{tabular}{||c|c|c|c||}
\hline \hline Municipio & Número de eventos bélicos & Municipio & Número de eventos bélicos \\
\hline Argelia & 122 & El Tambo & 48 \\
\hline Toribio & 104 & Miranda & 41 \\
\hline Corinto & 93 & Jambaló & 39 \\
\hline Caloto & 84 & Suárez & 38 \\
\hline Caldono & 51 & Santander De Quilichao & 37 \\
\hline
\end{tabular}

Fuente: OCHA. Sistema de información humanitaria [Sidhi].

Figura 4. Índice de Riesgo de Situación Humanitaria (2010)

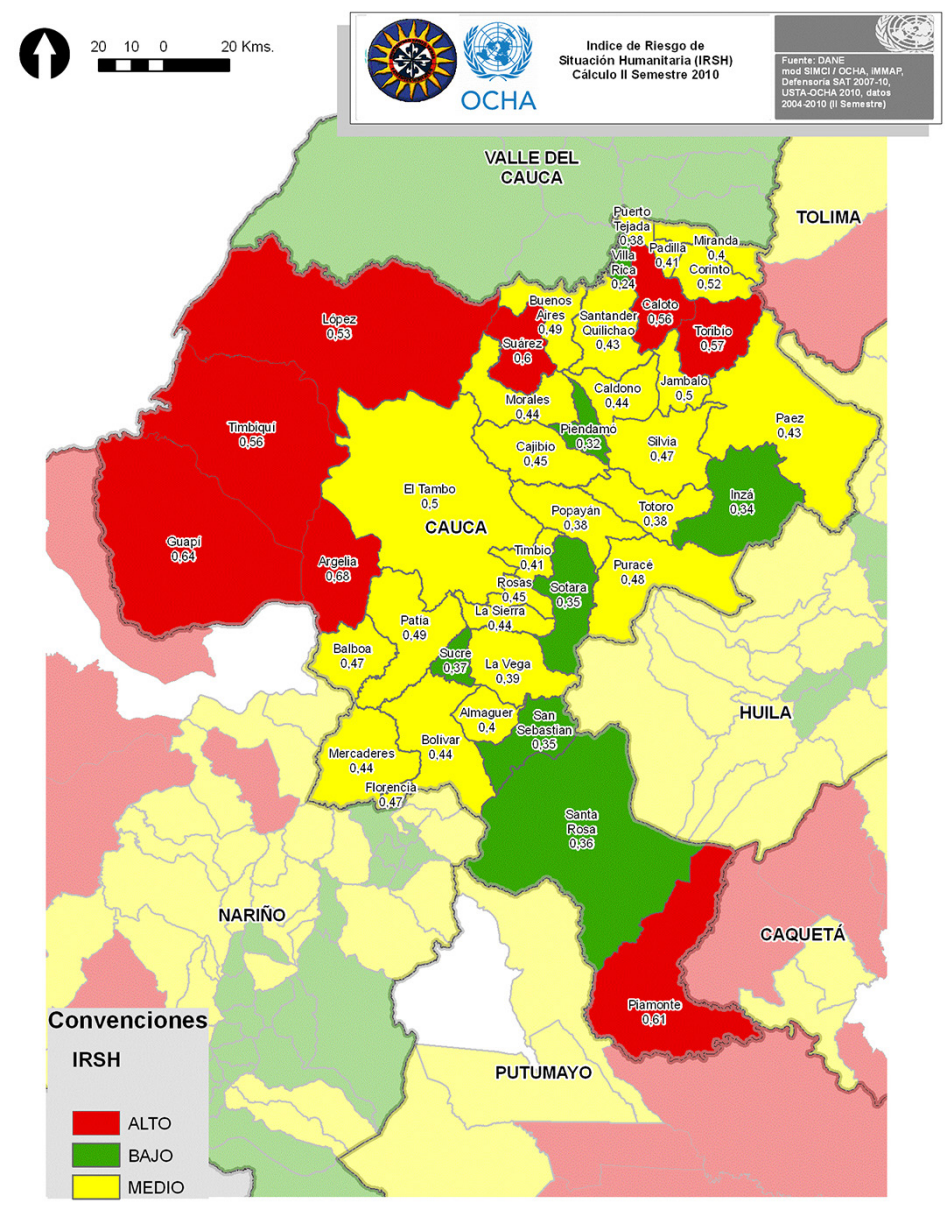

Fuente: Universidad Santo Tomás [USTA] y OCHA (2010). Datos 2004-2010 (II semestre).

4 OCHA. Sistema de información humanitaria [Sidhi]. 
A modo de síntesis de los indicadores anteriores contamos con el Índice de Riesgo de Situación Humanitaria. El IRSH está conformado por el cálculo de dos dimensiones: la vulnerabilidad y la amenaza. En la primera se considera como factor la capacidad de respuesta y en la segunda el conflicto. Los indicadores de la vulnerabilidad hacen referencia al nivel educativo, cobertura sanitaria, acceso a los servicios de agua y energía, la oferta institucional y otros indicadores económicos. Los indicadores del conflicto son los relativos a acciones bélicas, incidentes con minas, homicidios, secuestros y existencia de grupos armados (USTA y OCHA, 2009). El IRSH establece en una escala de 0 a 1 , donde 0 es ningún riesgo identificado y 1 es máximo riesgo identificado que tiene un municipio de enfrentar una situación humanitaria.

El mapa del IRSH en Cauca nos muestra unos valores muy elevados de dicho índice, con la mayor parte de los municipios en situación de riesgo medio o alto, y tan solo 6 -de los 41 municipios de Cauca- que escapan a una posible focalización de las ayudas humanitarias. La probabilidad de ocurrencia de crisis humanitarias, causadas por amenazas y vulnerabilidad en los municipios de Guapi, Argelia, Tinbiqui, López o Suárez -situados en la Cordillera Occidental- supera el 0,50. Y la mayor parte del Valle del Magdalena se mantiene con valores medios, superiores al 0,40. Otra de las particulares de Cauca es que el riesgo de amenaza afecta de igual manera a los municipios más poblados y urbanizados como a las zonas rurales del departamento.

\section{CARACTERIZACIÓN DE LOS DESPLAZAMIENTOS INTERNOS}

Los desplazados internos ${ }^{5}$ son los individuos o grupos de personas que han sido forzados a huir de sus hogares para escapar del conflicto armado, la violencia generalizada o los desastres naturales. La diferencia con los refugiados radica en que cuando un civil que huye cruza la frontera internacional de su país se convierte en un refugiado. Estas personas que se encuentran en un círculo interminable de violencia constituyen ya una nueva categoría social en Colombia según Osorio Pérez (2001).

La Consultoría para los Derechos Humanos y el Desplazamiento [CODHES] (2014) considera que la cifra real de desplazados por el conflicto armado interno en Colombia entre 1985 y 2013 es de 5.921 .924 personas. Esto significa, de acuerdo con las estimaciones mundiales de Internal Displacement Monitoring Centre, que Colombia es el segundo país en el mundo con mayor número de desplazados internos. Pese a los procesos de paz en curso, y según las investigaciones del Centro de Seguimiento del Desplazamiento Interno, que forma parte del CNR, hubo 156.918 nuevos casos de desplazamiento en 2013 en ese país. El fenómeno del desplazamiento en Colombia no solo es el más numeroso de Latinoamérica sino también uno de los más antiguos, pues comenzó en 1960 y se calcula que ya el $12 \%$ de la población nacional vive desplazada. El departamento del Cauca ha sido uno de los que más ha sufrido el conflicto interno y, por tanto, tampoco ha estado exento de los numerosísimos desplazamientos forzados que asolan al país. Así el desplazamiento reciente acumulado en Cauca entre 2007 y 2014 alcanza a 210.240 personas (OCHA-Sidih, 2014).

Entender el desplazamiento forzado supone entender la naturaleza del conflicto colombiano y la dinámica de los poderes regionales y locales, como ya apuntaba Zuluaga (2004). Pero es más, los desplazamientos son causa y efecto de la actual situación de Colombia. Están originados por los conflictos internos y son causa de graves impactos sociales y espaciales: de la desigualdad social, de la descampesinización, de modificaciones en la estructura de la propiedad. En definitiva, de profundas modificaciones en los espacios rurales y de una desarticulación del territorio sin precedentes. Igualmente ocasiona vertiginosas transformaciones en los espacios urbanos con la creación de cinturones de pobreza. Todo ello sin olvidar los importantes impactos paisajísticos y medioambientales que acompañan estas transformaciones, como la desforestación o la contaminación que amenaza a un país privilegiado por la naturaleza.

\section{1. ¿Quiénes se desplazan?}

Los desplazados pertenecen en su mayoría a comunidades étnicas, afrocolombianas e indígenas y son en su gran mayoría campesinos pobres. La profesora Bello y Peña (2000) caracteriza a los desplazados como personas que secularmente han estado excluidas de los beneficios de los modelos de acumulación

5 "Es desplazada toda persona que se ha visto forzada a migrar dentro del territorio nacional abandonando su localidad de residencia o actividades económicas habituales, porque su vida, su integridad física, su seguridad o libertad personales han sido vulneradas o se encuentran directamente amenazadas, con ocasión de cualquiera de las siguientes situaciones: conflicto armado interno, disturbios y tensiones interiores, violencia generalizada, violaciones masivas de los derechos humanos, infracciones al derecho internacional humanitario..." (Artículo $1^{\circ}$ de la Ley 387 de 1997). 
y participación política, y que culturalmente han sido invisibilizadas, pero han logrado sobrevivir con sus propios recursos, medios de economía sostenible y culturas ancestrales. Para muchos de los desplazados no ha existido la ciudadanía y desconocen la noción del Estado, por lo menos la de Estado social de derecho. Ahora sus territorios atraen las miradas rapaces que ven en sus tierras riquezas minerales y naturales o ventajas geoestratégicas. Las comunidades son disputadas como bases de apoyo y conocen al Estado no por su presencia social, sino represiva. Es así como estas comunidades, que permanecieron por muchos años al margen, hoy son incluidas en la política para su explotación y control. De esta manera el desplazamiento forzado se suma a la larga cadena de vulneraciones de indígenas, afrocolombianos, colonos, aparceros, jornaleros y campesino, quienes han sido puestos al margen de los beneficios de la economía y el "desarrollo".

Los campesinos, y dentro de ellos los afrodescendientes e indígenas, son los más afectados. Mujeres, niños y niñas indígenas y negros constituyen el principal colectivo víctima del desplazamiento forzado. El 33\% de los desplazados pertenecen a las comunidades negras (CODHES, 2003), es decir 957.000 personas. La tasa de expulsión de estas comunidades es un $20 \%$ mayor que la del resto del país, siendo el Chocó el primer departamento expulsor. La población indígena desplazada representa el 5\% del total de desplazados, dato muy significativo si se tiene en cuenta que la población indígena se corresponde con el $2 \%$ de la población total del país. El mayor grupo de víctimas son mujeres, niños y niñas -hasta un $83 \%$ de la población que se desplaza (Alto Comisionado de las Naciones Unidas para los Refugiados [ACNUR], 2009) - y muchas de ellas se han convertido en jefas únicas de hogar a causa de la muerte o reclutamiento de sus compañeros.

\section{2. ¿A dónde se desplazan?}

Afirmábamos que el desplazamiento acumulado en Cauca hasta 2014 afectaba a un total de 210.240 personas. Los últimos datos de $\mathrm{OCHA}^{6}$ cifran en 11.308 individuos el desplazamiento masivo intramunicipal desde 2008, en 7.750 el desplazamiento masivo interdepartamental, en 5.501 el desplazamiento masivo interveredal y en 11.876 el número de personas afectadas por el confinamiento o bloqueo de comunidades.

Tabla 2. Municipios con mayor número de desplazamientos en Cauca en 2011

\begin{tabular}{|c|c|c|c|}
\hline \multicolumn{2}{|c|}{ Expulsiones } & \multicolumn{2}{|c|}{ Recepción/Estimado Llegadas } \\
\hline Municipios & Cantidad & Municipios & Cantidad \\
\hline Timbiquí & 3.161 & Popayán & 5.355 \\
\hline Guapi & 2.339 & Timbiquí & 1.607 \\
\hline El Tambo & 2.245 & Guapi & 565 \\
\hline Argelia & 2.084 & El Tambo & 563 \\
\hline Bolívar & 1.485 & Santander De Quilichao & 262 \\
\hline López & 1.025 & Morales & 216 \\
\hline Patía & 724 & Timbío & 201 \\
\hline Mercaderes & 638 & Argelia & 157 \\
\hline Cajibío & 630 & Mercaderes & 152 \\
\hline Morales & 500 & Patía & 140 \\
\hline
\end{tabular}

Fuente: OCHA. MONITOR Sala de Situación Humanitaria.

Los desplazamientos forzados se producen en primer lugar en las zonas veredales, generándose un éxodo hacia las cabeceras municipales. Sin embargo, el escalonamiento del conflicto obliga a que el éxodo continúe hacía las grandes ciudades, donde son mayores las posibilidades económicas o de anonimato. En consecuencia, ciudades como Bogotá, Medellín, Calí, Cartagena, Barranquilla, y las capitales departamentales experimentan un proceso continuo y masivo de llegada de población que modifica significativamente los niveles de empleo, mendicidad y marginalización en las ciudades.

6 OCHA. MONITOR Sala de Situación Humanitaria. 
Popayán, capital del departamento de Cauca, se ha convertido, junto con los principales núcleos de población del departamento (Timbiquí, Guapi, El Tambo, Santander De Quilichao, Morales y Timbío) en el centro receptor de la población desplazada de los departamentos vecinos como el propio Timbiquí, Guapi, El Tambo, Argelia o Bolívar, tal y como se aprecia en la tabla 2.

Pero la salida, masiva o individual, hacia las cabeceras municipales o las ciudades no es la única forma de desplazamiento: las comunidades han generado formas de salvaguardar su subsistencia sin renunciar a sus territorios. Es el caso de algunas comunidades que huyen temporalmente, internándose en la selva o las montañas, hasta tanto disminuyan o cesen los hostigamientos o enfrentamientos para poder retornar.

\section{LAS CAUSAS DE LOS DESPLAZAMIENTOS}

Las causas de los desplazamientos no son únicas y suelen aparecer concatenadas. Además se podrían diferenciar unas causas inmediatas de otras principales que son las que causan aquellas. Entre las causas inmediatas podemos destacar: la consideración de las víctimas de que la vida propia y la de su familia se encuentran amenazadas, las ocasionadas por la presencia de combates cercanos en las zonas rurales y las derivadas de la pérdida de medios de subsistencia. Dichas causas inmediatas a su vez responden, en última instancia, a la propia dinámica del conflicto armado, a la posición geoestratégica de Cauca y a los intereses económicos que se han generado en este departamento.

\subsection{El enfrentamiento armado}

Los grupos paramilitares y guerrilleros, junto con las bandas criminales, son los responsables directos de provocar los desplazamientos masivos -esto es, de más de 50 personas-además de cometer secuestros, asesinatos o desapariciones. Los paramilitares, en la lucha contra las guerrillas, consideraron a la población civil como objeto militar y no dudaron en usar contra ella la violencia cuando toman las poblaciones, destruyendo sus viviendas y campos de cultivo, como refleja la Alta Comisionada de las Naciones Unidas para los Derechos Humanos en sus informes sobre Colombia (Oficina del Alto Comisionado de las Naciones Unidas para los Derechos Humanos [OACNUDH], United Nations High Commissioner for Human Rights [UNHCHR], 2013). Por otra parte, los acuerdos y la política de Seguridad Democrática, fundamentada en la inversión militar, la toma de posiciones del ejército en las zonas estratégicas y el fortalecimiento de las medidas de seguridad, parecen quedar en entredicho cuando se examinan las estadísticas, en las que son más los que se desplazan que los que retornan a sus tierras.

La presencia de las guerrillas en el departamento es histórica y han tenido representación en el todos los grupos guerrilleros: Las Fuerzas Armadas Revolucionarias de Colombia [FARC], el Ejército Popular de Liberación [EPL], el Ejército de Liberación Nacional [ELN], el Movimiento Quintín Lame, el Movimiento 19 de Abril [M-19], el Movimiento Jaime Bateman Cayón, el Partido Revolucionario de los Trabajadores [PRT], el Comando Pedro León Arboleda y el Comando Ricardo Franco Frente-Sur.

La desmovilización del Bloque Calima de las Autodefensas Unidas de Colombia [AUC] no ha supuesto el fin del paramilitarismo en el Cauca, pues se han integrado muchos de sus antiguos militantes en bandas criminales o bacrim. Así los narcoparamilitares de los Urabeños, los Rastrojos y las Águilas Negras, con organización y estructura armada controlan territorios con la complicidad del poder político y la fuerza pública (Instituto de estudios para el desarrollo y la paz [INDEPAZ], 2013). Los móviles de estos grupos son el "control social", el narcotráfico, la extorsión y el robo para la obtención de lucro económico. Con estos fines no dudan en el extermino de líderes e integrante de organizaciones sociales de la región. En el ejercicio de esta violencia cuentan en ocasiones con la aquiescencia e incluso connivencia, ya sea por corrupción o amenazas, de miembros de la fuerza pública, incluida la Policía Nacional (OACNUDH, UNHCHR, 2012).

Pero Cauca destaca también por ser uno de los departamentos de mayor movilización social y resistencia indígena y afrodescendiente del país. Los procesos de resistencia expresan el significado fundamental que contiene el territorio para la existencia misma de las comunidades y en este sentido su firme decisión de luchar por lo que representa el derecho a la autonomía y la tierra.

Las organizaciones indígenas se agrupan en el Consejo Regional Indígena del Cauca [CRIC] y han centrado su lucha en la titulación colectiva de la tierra y en la creación de resguardos indígenas que les permitan conservar sus costumbres. En sus territorios practican una silvicultura ligada a las actividades 
tradicionales desde una particular cosmovisión de la tierra. Rechazan por igual la presencia de actores armados, pidiendo la salida de sus territorios de la guerrilla, del ejército y la policía. Su resistencia es pacífica en forma de movilizaciones conjuntas, si bien este tipo de resistencia les sigue cobrando víctimas, entre sus líderes o los defensores de los derechos humanos. Podemos señalar como principales hitos del movimiento social caucano: la Cumbre Nacional de Organizaciones Sociales realizada en el 2004, la oposición al Tratado de Libre Comercio [TLC] en 2005, la propuesta de Parlamento Indígena en el 2007, la Minga de resistencia social de 2008 o la declaración de Toribio en 2011, que reitera diferentes propuestas para terminar la guerra, defender la autonomía, reconstruir los bienes civiles y construir la paz (Junta Directiva Regional de Cabildos Indígenas del Cauca, 2011).

La resistencia afrodescendiente es igualmente pacífica. Las comunidades de los municipios del Pacífico (López de Micai, Timbiquí y Guapi) consiguieron los títulos para sus territorios colectivos en la Ley 70 de 1993 y ya existen 17 consejos comunitarios con títulos colectivos en los tres municipios pacíficos que tienen tituladas más de medio millón de hectáreas de manera colectiva, sin embargo las de los Valles Interandinos los están reclamando en el presente. Ahora en todas las comunidades se manifiesta una clara oposición a la minería ilegal y la extensión de los cultivos industriales e ilícitos. Los afrodescendientes no solo han desarrollado proyectos productivos, que les ha permitido empoderarse de sus recursos naturales en forma acorde con su cultura y necesidades, sino que también han prevenido el desplazamiento forzado y promovido el retorno de población desplazada a sus lugares de origen, gracias también a que las tierras y tiendas comunitarias han garantizado la seguridad alimentaria en los momentos más crudos del conflicto armado.

La resistencia civil de indígenas y afrodescendientes en Colombia puede ser entendida como un proceso de empoderamiento pacifista en Colombia, uno de los países con mayor número de iniciativas civiles de paz en el mundo como afirma Hernández Delgado (2009). Así "el concepto de resistencia civil ha estado ligado a una dimensión tradicionalmente conocida y a otra de origen reciente (...) La primera, como método de lucha política, y la segunda, como sistema de defensa" (Hernández Delgado, 2009, p. 123). Este mecanismo de lucha y de defensa no solo ha logrado el reconocimiento de los pueblos indígenas y de la diversidad étnica en la constitución de 1991 sino que deviene, en definitiva, en una propuesta de transformación para la paz que permite evitar los trasvases de población, fija la población rural y edifica un modelo de desarrollo sostenible respetuoso con los ecosistemas, sin esquilmar los recursos de la naturaleza. La resistencia civil que se manifiesta en acción colectiva se cimenta en una fuerza moral que se nutre en algunos casos, de cosmovisiones milenarias, construye autonomías reales, desde cada una de las comunidades, propiciando la autodeterminación como pueblo (Secretaria General de la Comunidad Andina, 2009).

\subsection{La posición geoestratégica del Cauca}

El mapa del desplazamiento forzado en Colombia dibuja que las zonas en donde se produce mayor número de expulsiones forzadas son aquellas que revierten mayor valor estratégico, como es la región del Cauca, en razón de su condición como corredor de tránsito de armas, paso de ejércitos o circulación de productos ilícitos y por tratarse de un espacio de fronterizo en donde se pueden replegar los grupos armados.

En este momento el Cauca es un corredor en disputa por el control del tráfico de drogas y la movilidad de armas que comunica al propio departamento y a los departamentos de Tolima y el Valle del Cauca. Así, la ruta que recorre la cadena de estos negocios ilegales se expande desde el Norte del Valle hasta las salidas al Pacífico. El control de los grupos armados no solo tiene como objetivo el dominio de la carretera Panamericana y las salidas al mar sino que cubre extensos territorios en López, Timbiquí y Guapí (Salas Salazar, 2010).

Además de ser un corredor natural el Cauca, existe una vinculación directa del departamento con los procesos de integración económica del Pacífico, pues el Gobierno colombiano ve un trampolín en el foro de Cooperación Económica Asia-Pacífico [APEC] para acceder a los mercados del Pacífico y Asía, junto a México, Chile y Perú como socios. Ello supondría la creación de un corredor internacional en el pacífico colombiano.

Por otro lado la posición estratégica del Cauca se pone de manifiesto en la cercanía de parte de sus territorios, como Toribio, a Cali, la tercera ciudad más grande del país. Esto explica el intento de las FARC 
de permanecer en el territorio, al tiempo que a las fuerzas armadas les perturba dicha presencia, que se valora por una parte de la opinión pública como una muestra de la flaqueza de la política de seguridad del actual gobierno de Santos.

\subsection{Los intereses económicos}

El desplazamiento forzado no es sino una estrategia de guerra que responde a móviles económicos y al control de los territorios (Rojas y Romero, 2000). Los desplazados no son desplazados "por la violencia": la violencia es sólo el instrumento que se utiliza para expulsar a la población. En última instancia las poblaciones indígenas y campesinas son despojadas de sus tierras por los mecanismos de adecuación a las necesidades de producción y acumulación que el capitalismo impone y la estrategia de dominación de los diversos sectores que se disputan el poder, que se sostiene por el acopio y especulación de los abundantes recursos naturales de Colombia y que vienen demandando los mercados internacionales (Bello, 2004).

En las últimas décadas en Colombia, al igual que en otros países latinoamericanos, se consolida el modelo neoliberal y actúan los llamados procesos de modernización del Estado, los cuales implican la redefinición del territorio y sus relaciones de acuerdo a las necesidades de producción y comercialización que dicho modelo demanda, pero sin reparar suficientemente en los costos medioambientales, sociales, y culturales que significan. Pero indudablemente son las zonas en donde se localizan los recursos naturales los escenarios que vienen a convertirse en zonas de disputa por los distintos actores que intervienen en dichos territorios. Así los espacios ocupados por la agricultura o la ganadería tradicional sufren la presión de los cultivos industriales o ilícitos, o los enclaves mineros que son explotados por comunidades indígenas o afro con técnicas tradicionales experimentan usurpaciones por parte de concesiones mineras particulares y de grandes multinacionales mineras.

Para acceder a estas riquezas y adecuarse a la dinámica del mercado global son precisas una serie de infraestructuras que Colombia comienza construir y que comportan unos costos económicos y sociales ingentes, costos que el modelo neoliberal del Estado se encuentra dispuesto a acometer en forma de grandes megaproyectos minero-extractivos, energéticos o agroindustriales: vías nacionales y regionales, puertos y aeropuertos, grandes presas y embalses, plantas eléctricas, etc.

La construcción de los megaproyectos es facilitada por el IIRSA (Iniciativa para la Integración de Infraestructura Regional en Suramérica), los TLC (Tratado de Libre Comercio), el ALCA (Área de Libre Comercio de las Américas) y el IRA (Iniciativa Regional Andina). Se trata de tratados económicos internacionales que son ratificados por los gobiernos colombianos y que proveen de créditos y tecnología a la realización de los megaproyectos. Pieza fundamental son también los planes Colombia, Patriota y la aplicación de la Doctrina de Seguridad Democrática. Todos forman parte de un mismo proceso anunciando la integración de los recursos colombianos dentro de la lógica del nuevo modelo económico neoliberal que lidera Estados Unidos. El modelo planteado por el IIRSA en Cauca tendría dos ejes: El eje interandino que abarcará el valle del Magdalena hasta Santander y San Cristóbal (Venezuela) y el otro el Amazonas que integraría el Huila, Cauca y Nariño hasta Ecuador (Instituto Nacional Sindical, 2005). El eje Interandino pretende facilitar el transporte entre los distintos sectores estratégicos de la región: la agricultura, la agroindustria, la minería y los hidrocarburos. El eje Amazonas se planea para desarrollar actividades que explotan el petróleo y gas, la biotecnología, la pesca, la producción de madera, caucho, cacao, caña, alcohol, frutas, café, algodón, artesanías y el ecoturismo.

Estos proyectos suponen un coste ambiental y humano del que se hacen eco la Coordinadora Andina de Organizaciones Indígenas [CAOI] en una resolución de los pueblos indígenas sobre el IIRSA del 19 de enero de 2008 (CAOI, 2008), en donde muestran sus preocupaciones frente a los efectos devastadores que ya han tenido las primeras aplicaciones de los planes del IIRSA. En efecto, se desarrollaron proyectos de construcción de represas hidroeléctricas, así como proyectos de deforestación que implementaban las empresas de madera, o proyectos de explotación minera y de construcción de carreteras para facilitar el transporte de todas estas materias primas. En este sentido, los territorios son despoblados y repoblados al antojo de los actores armados. Las acciones de expulsión no cesan sin embargo, pues las guerrillas intentan volver a ganar el control de sus antiguas zonas y continuamente despliegan acciones en este sentido (Molano, 2006). Algunos de estos megaproyectos en Cauca son: El embalse de Salvajina que regula el río Cauca o el proyecto de desviación del río Ovejas. 
La construcción del embalse de Salvajina en el municipio de Suárez supuso el desplazamiento de más de 3.000 campesinos que perdieron sus tierras más fértiles y no vieron cumplidas las promesas de las compensaciones del Acta 86. Aquellos que se negaron a marcharse fueron desplazados por el ejército y los grupos paramilitares. Algunos de los líderes de las organizaciones contrarias a su construcción incluso fueron asesinados. Este caso de despojo de las comunidades campesinas del Valle Alto del Cauca ha producido una ruptura no solo social, en donde la situación laboral se ha empeorado y la pobreza ha aumentado desde la construcción, sino una ruptura del territorio pues la represa obstaculizó los caminos que campesinos e indígenas habían construido. Los puentes prometidos nunca llegaron y los medios tradicionales de subsistencia nunca fueron reemplazados, en detrimento perpetuo de estas poblaciones. Las actividades de subsistencia que tenían lugar en la zona -entre las que se encontraban la minería y la agricultura- cambiaron para muchos habitantes de la región, puesto que las tierras fértiles quedaron sumergidas en el embalse.

El proyecto de desviación del río Ovejas al Embalse la Salvajina para aumentar la capacidad hidroeléctrica de este ha encontrado una fuerte resistencia campesina -principalmente la afrocolombiana- pues atenta contra los medios tradicionales de subsistencia, al impedirles el derecho al acceso al agua. Dicho proyecto fue paralizado en 1993 por primera vez, después en el 2005, y más recientemente en el año 2007.

En definitiva los actores que ocasionan el desplazamiento son las guerrillas, los militares, paramilitares, ganaderos, narcotraficantes, empresas nacionales y transnacionales. Y las causas señaladas nos permiten develar los nexos del desplazamiento forzado con los patrones de acumulación de capital. Es así como cobra pleno significado la afirmación de que "no hay desplazados porque hay guerra, sino que especialmente hay guerra para que haya desplazados" (Valderrama y Mondragón, 1998, p. 58).

\section{CONSECUENCIAS DE LOS DESPLAZAMIENTOS HUMANOS}

Las consecuencias de los desplazamientos forzados son devastadoras, no solo en el ámbito sociodemográfico, sino que además inducen profundas secuelas territoriales en los espacios agrarios, urbanos o en los espacios naturales y protegidos.

\subsection{Consecuencias sociodemográficas}

Los desplazamientos humanos son el efecto más notorio de la violencia armada, pero también las poblaciones desplazadas pierden sus posesiones personales y el acceso a sus medios de subsistencia tradicionales, a sus tierras de cultivo, negocios, etc. Además de las pérdidas materiales y económicas, existen otras que afectan a la estructura familiar e incluso al equilibrio personal, manifestándose en alteraciones psicológicas. La fractura en las unidades familiares por la perdida, en la mayor parte de los casos del hombre, genera efectos negativos tanto sobre la parte superviviente de la pareja como sobre los hijos y otros familiares. La violencia familiar, el maltrato infantil, el abandono de los estudios o el ingreso en las filas de alguna de las organizaciones ilegales vienen ser algunas de las consecuencias de la desestructuración familiar. Los desplazados, no solo deben buscar una nueva reubicación espacial, sino nuevas ocupaciones que le garanticen el sustento, además de nuevas identidades culturales y territoriales. Pero, en la mayoría de los casos, el desarraigo no se resuelve satisfactoriamente y se traduce en la precarización de las formas de vida, en la mendicidad, en la delincuencia y en un creciente descontento social, dándose el caso de que la población desplazada acaba por ser la más marginada dentro de los propios marginados y excluidos de la sociedad.

Esta pérdida de capital social y empobrecimiento poblacional afecta de forma particular a los grupos humanos afrodescencientes e indígenas. Los afrocolombianos son una de las poblaciones más vulnerables a los efectos del conflicto armado, y por ende uno de los focos más importantes de la protección ante los riesgos de desplazamiento forzado.

\subsection{Consecuencias territoriales}

Además de los impactos sociodemográficos señalados también se están produciendo cambios profundos en el territorio que afectan, no solo a la región objeto de estudio, sino a todo el país. Esta significación cambiante del territorio viene determinada por diversos actores ajenos y se opera por procesos violentos sobre la población. Supone la construcción de diferentes territorialidades sobre unos modelos que conllevan modificaciones en los espacios rurales, en las áreas urbanas y en las zonas naturales y protegidas. 


\subsubsection{Consecuencias en los espacios rurales}

Las modificaciones en los espacios rurales son las que mayor impacto presentan en razón de su extensión, pues es de ellas de donde parte la población desplazada. Igualmente son las que mayor gravedad presentan por la casi imposibilidad de invertir procesos como: la descampesinización, la relatifundización, o el cambio en el mapa de cultivos.

La población campesina que ha sido desplazada es aquella que trabaja unas tierras que ahora se valorizan de forma diferente a los usos tradicionales, y en consecuencia, al modificarse el tipo de propiedad y de explotación, se modifican dichos usos, desapareciendo incluso el aprovechamiento agrario original, como es el caso de su sustitución por actividades extractivictas.

Es así como se produce una desarticulación de territorios construidos a lo largo de muchas generaciones, en donde tenían cabida espacios para los cultivos, para la silvicultura, la pesca, la recolección de plantas medicinales, el barequeo tradicional, o el trazado de redes de comunicación ancestrales, como son los caminos veredales, etc. Paisajes agrarios excepcionales, muchos desaparecidos y de los cuales no queda constancia si no es por los mapas que han dibujado las propias comunidades indígenas (figura 5). Particular importancia está teniendo la desaparición de las producciones de subsistencia y de aquellas que se orientaban a los pequeños mercados locales o incluso regionales, comprometiéndose de este modo la soberanía alimentaria de la región.

Figura 5. Mapas sociales de la cuenca alta del río Cauca: El Hormiguero y la Toma
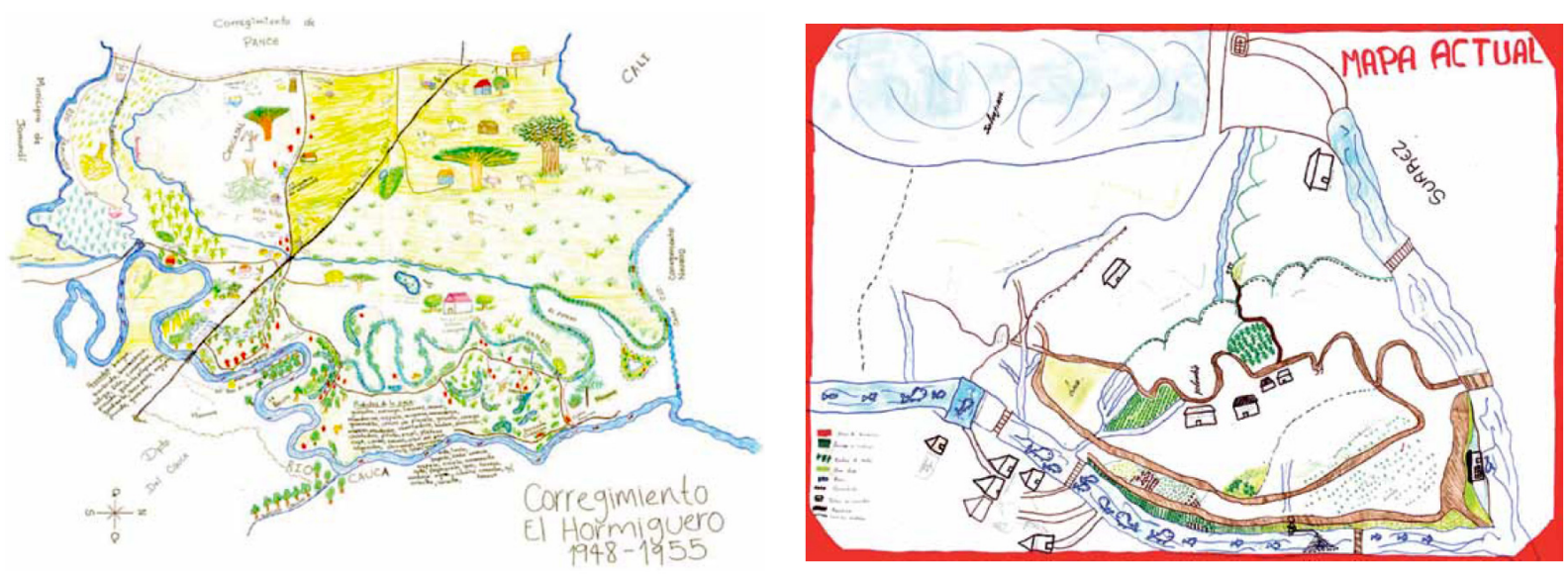

Fuente: Vélez Torres, Rátiva Gaona y Varela Corredor (2012).

Los modelos productivos que se están imponiendo son incompatibles con las formas tradicionales de tenencia y uso de la tierra, igual que la explotación incontrolada de los recursos naturales para la exportación o la búsqueda de beneficios económicos inmediatos para las empresas y grandes compañías. Como señala la Conferencia Episcopal de Colombia (1999), conectar el tema del desplazamiento forzado y el conflicto agrario permite mostrar algunos de los intereses que ven en el desarraigo la forma más económica, de conseguir la acumulación de tierras previamente acondicionadas y, por ende, valorizadas por el trabajo campesino. De los 15,5 millones de campesinos que existían en 1990 en Colombia, al menos 5 millones han abandonado el campo o las labores agrícolas tradicionales en dicha década. Este desplazamiento masivo de población rural generó un fenómeno de abandono de tierras que en fechas recientes se estima en 6,5 millones de hectáreas, es decir, aproximadamente un $11 \%$ de la superficie agropecuaria ha sido despojada y abandonada (Machado Cartagena, 2013). Dichas extensiones, en la mayoría de los casos, son ocupadas por los actores armados, pues su control forma parte de una estrategia de guerra de posiciones. También son los terratenientes, los narcotraficantes o los medianos hacendados los que ocupan las tierras a muy bajo costo, valiéndose de pistoleros o retitulándolas de forma fraudulenta.

En Cauca han sido los campesinos que trabajan las pequeñas y medianas propiedades los más desposeídos. Por ejemplo, las operaciones militares llevadas a cabo en el Alto Guapi en mayo de 2015 han supuesto el abandono de tierras y el desplazamiento a la cabecera municipal de 110 familias, 463 personas, cifras registradas por la Defensoría Regional del Pueblo en el Cauca y la Pastoral Social del Vicariato 
Apostólico de Guapi. En Cauca predomina la estructura de mediana propiedad, con un 44 por ciento de la propiedad privada asignada a predios entre 20 y 200 hectáreas. El departamento ha experimentado en la década 2000-2009 una marcada tendencia a la concentración de tierras. Además la dinámica de concentración se está presentando en las tierras de mejor calidad, entre la Cordillera Central y Occidental, en los Valles del Cauca y Patía. El cálculo de diferentes coeficientes aplicados por el Instituto Geográfico Agustín Codazzi [IGAC] (2012), indica que la concentración de la tierra en el departamento está determinada por un reducido número de propietarios con predios sumamente grandes. En definitiva, el patrón de concentración de la tierra es debido a las políticas públicas sectoriales o macroeconómicas que han privilegiado la agricultura comercial y extensiva, pero en gran medida es causado por "las adquisiciones masivas que han hechos sectores del narcotráfico y de los grupos armados ilegales" (IGAC, 2012b, p. 71).

Los cambios en la propiedad inducen una modificación en los aprovechamientos agrarios, de forma que van desapareciendo los tradicionales cultivos de subsistencia y de aquellos que se orientaban a los mercados locales. Los nuevos modelos productivos y la necesidad de financiar el conflicto o alimentar el narcotráfico han hecho crecer los cultivos industriales, los ilícitos y la ganadería extensiva. La producción se dedica a la exportación y arriesga de este modo la soberanía alimentaria del país. Además, los tratados de libre comercio obligan a los campesinos a competir con los productos europeos y de Estados Unidos. De ello da cuenta la balanza comercial colombiana en el 2014: el déficit alcanzó el récor histórico de 6.293 millones de dólares. Las importaciones del sector agropecuario supusieron 2.513 millones de dólares, cifra que no deja de crecer y que triplica ya las cifras del año 2000 (DANE, 2015).

El maíz, la papa, la yuca o el frijol son los tradicionales cultivos anuales de sembradura. Entre los cultivos permanentes destaca el café, la caña, el plátano y el cacao. Si bien muy pocos de los suelos del departamento tienen vocación hacia la ganadería esta no cesa de crecer, y cerca de un millón de hectáreas se dedican a esta actividad. Si a finales de siglo existían 245.000 reses en Cauca, hoy en día superan las 369.000 (DANE, 2013).

El cultivo de coca y amapola implica modificaciones sobre los tradicionales esquemas de uso y tenencia de la tierra. Igualmente suponen una gran presión sobre la propiedad existente pues es requerida para la inversión y lavado de los abundantes capitales que se generan. Los procesos de adecuación de la tierra a las necesidades del narcotráfico, dejan como resultado la consolidación de patrones de concentración de la tierra, conformando nuevos procesos de descampesinado y relatifundización (Bello, 2004).

Los cultivos ilícitos se localizan sobre todo en la región Pacífica y en la Cordillera Occidental en aquellas zonas que escapan al control efectivo del Estado y afectan sobre todo a los municipios de: El Tambo, Timbiquí, Guapi, Piamonte, López, Argelia, Mercaderes, Balboa, Patía y Morales. El sistema de teledetección del SIMCI (Sistema Integrado de Monitoreo de Cultivos Ilícitos) de UNODC (Oficina de las Naciones Unidas contra la Droga y el Delito) nos arroja datos recientes y bastante exactos: el cultivo de coca había permanecido en niveles relativamente bajos hasta 2006 en Cauca, a partir de ese año el área sembrada se triplicó alcanzando en 2009 un total de 6.597 hectáreas. En 2013 se mantuvo la tendencia a la reducción iniciada en 2012 llegando a 3.326 ha. Dicha reducción se operó en la parte montañosa del departamento, mientras que en la zona costera predominó la tendencia al incremento (UNODC, 2014).

Es de esta manera como se entrelazan en los espacios agrarios de Cauca un tradicional modelo de exclusión del campesinado, nuevas presiones derivadas de las imposiciones del ordenamiento mundial, el mercado de los cultivos ilícitos y la disputa territorial de los actores armados. Estos factores se articulan configurando un nuevo mapa del territorio y una expulsión superior a doscientas mil personas.

\subsubsection{Consecuencias en los espacios urbanos}

Desde un punto de vista territorial los desplazamientos forzados tienen un considerable impacto en las zonas de llegada de esta población, que mayoritariamente tiene como destino los espacios urbanos. Estos flujos comportan una serie de procesos o etapas intermedias como son el desplazamiento intrarural, el confinamiento y el desplazamiento intraurbano (CODHES, 2013). El desplazamiento intrarural ocurre en las primeras etapas del desplazamiento, cuando las personas o comunidades resisten el desplazamiento, permaneciendo en su región con el fin de evitar el despojo patrimonial y cultural. El confinamiento se refiere a los controles de movilidad que se imponen a la población con sistemas de coerción legal e ilegal que operan en los territorios de conflicto. El desplazamiento intraurbano es la evidencia de la extensión del conflicto armado a las ciudades y demuestra el interés de los poderes fácticos por imponer su dominio también en 
las zonas urbanas. Este tipo de desplazamiento afecta tanto a los que ya son residentes como a las personas que han vivido ciclos de desplazamiento forzado, obligándoles a modificar su barrio de residencia, o incluso a cambiar de ciudad. Medellín fue un claro ejemplo de este tipo de desplazamientos hace una década, pero este fenómeno se está produciendo ya en las principales ciudades de Colombia, incluida Popayán.

El desplazamiento urbano en sus diferentes variables ha radicalizado la demanda por empleos, vivienda e ingresos en urbes segregadas, que no estaban preparadas para ello, pero que tampoco han sido objeto de reformas urbanas basadas en modelos inclusivos. De ahí que predomine una notoria desarticulación espacial en la nueva estructura urbana, la precariedad y la desigualdad en los servicios públicos, el asistencialismo y la marginalidad en las formas de vida urbana, que afecta no solo a la mayor parte de las víctimas de los desplazamientos sino a los ya enormes contingentes de pobres ya existentes. Los desplazados comparten su espacio con comunidades ya asentadas en los barrios de aluvión. Lo que en Colombia se denominan barrios "subnormales" o "barrios piratas", suburbios que crecen sin planificación urbanística ni apoyo de las autoridades. Sectores marginados que van tejiendo un abanico en torno a los barrios periféricos ya consolidados de la ciudad.

En Popayán se localizan en las Comunas 2 y 7, en la Loma de la Virgen y en la Vereda González, también en zonas rurales próximas como Las Guacas y en algunos de los antiguos asentamientos post-terremoto (1983) como son: Carlos Pizarro, 31 de Marzo, Las Palmas, Santiago de Cali, Los Pinos, Belén. También se anexan o superponen en Barrios ya consolidados como El Guayabal, Tomás Cipriano de Mosquera y Pandiguando (Guevara Corral, 2003) e (Instituto Nacional de Vivienda de Interés Social y Reforma Urbana, 1991). Todos ellos contrastan visiblemente con lo que llaman la "ciudad blanca" o el casco histórico colonial, uno de los mejor conservados de América Latina.

Las transformaciones urbanas que inducen los asentamientos informales responden a una intención de autogestión y autoproducción de hábitat por parte de los desplazados que llegan a la ciudad con la intención de construir una formalidad o proyecto de habitación, partiendo de la informalidad que supone la carencia de instrumentos o medios de planificación por parte de los municipios de acogida (Castillo de Herrera, 2009). Las tramas urbanas resultantes en Popayán o en Santander de Quilichao no son siempre ortogonales, en ocasiones dibujar trazados sinuosos como solución a las condiciones físicas y ambientales que imponen los relieves de los lugares de asentamiento o como imagen de la personalidad, tradición urbana y oral que la población desplazada importa de sus lugares de origen. Los agentes sociales que fabrican las nuevas barriadas crean igualmente diferentes modelos de gestión -las comunas- con sus propias instituciones vecinales e idiosincrasia.

El resultado es una ciudad no homogénea, el sumatorio de fragmentos físico-territoriales, económicos, sociales, culturales e incluso ambientales diferenciados. Por todo ello los impactos medioambientales resultan inevitables, comenzando por utilización de terrenos poco adecuados para edificar, la carencia de cobertura o acceso a los servicios públicos e infraestructuras. Cuando estos nuevos procesos urbanos $-\mathrm{y}$ Colombia se está consolidando como una sociedad urbana- no vienen acompañados de un proceso económico que pudiera absorber en los sectores formales esa mano de obra se crean cinturones de pobreza. Los desplazados son tratados como "pobres urbanos" y no ven reconocida su condición de víctimas de la violencia.

Es en las ciudades donde se juega buena parte de las soluciones de fondo a la problemática del desplazamiento forzado, pues en ellas coinciden las inseguridades humanitarias con las fragilidades sociales resultantes del desarraigo. En un contexto de conflicto se requieren soluciones tanto rurales como urbanas de carácter sostenible, pues lo que está en juego es la inserción productiva, social y cultural de millones de personas (CODHES, 2013).

\subsubsection{Consecuencias en los espacios naturales y protegidos: impactos paisajísticos y medioambientales}

Cauca conserva extensos espacios naturales escasamente modificados. La bota caucana que participa de la Amazonía alberga las mayores zonas de bosque autóctono, también abundantes en la costa pacífica o en las zonas montañosas de la cordillera Occidental y la cordillera Central. Estas zonas conservan su biodiversidad porque han sido habitadas por comunidades indígenas que han convivido con la naturaleza explotándola de forma sostenible a pequeña escala. Y de forma paradójica son estos habitantes ancestrales los que están siendo expulsados. Es por ello que para entender la dimensión de la devastación medioam- 
biental que sufre Cauca y buena parte de Colombia hay que acudir al análisis de las causas que lo provocan, fundamentalmente la extensión de los cultivos agroindustriales y la minería.

Los cultivos industriales que vienen desalojando a las comunidades campesinas junto a la ganadería extensiva son la palma de aceite y la caña, esta última en régimen prácticamente de monocultivo en el vecino Valle del Cauca. Los impactos medioambientales derivados son:

- La pérdida de biodiversidad por la sustitución de los mosaicos de cultivos tradicionales que cuentan con una resistencia y una adaptación al medio secular, mediante una adaptación inducida por la selección de semillas efectuada a lo largo de generaciones campesinas. En definitiva se produce la pérdida de la soberanía alimentaria.

- Empobrecimiento paisajístico en el que se desvanece la diversidad y matices del territorio en favor de un monocolor específico de cada plantación.

- La contaminación de los suelos y las aguas por el uso de plaguicidas.

- La sobreexplotación de cursos fluviales y acuíferos, particularmente en la agroindustria cañera.

- Modificación de los cauces fluviales por las nuevas infraestructuras hidráulicas con la consecuente, desforestación, pérdida de suelos y desaparición de la pesca fluvial.

- Desaparición de la "farmacia biológica", plantas medicinales -muchas de ellas endémicas-que las comunidades campesinas identifican, acotan y protegen en espacios concretos como se aprecia la cartografía social o mapas que dibujan dichas comunidades.

- Pérdida irreversible de las reservas de caza indígenas con la consecuente muerte de la fauna silvestre y del bosque autóctono.

- Se aumenta la posibilidad de ocasionar o amplificar las amenazas naturales recurrentes en Cauca como son: las inundaciones, avalanchas, etc. (Corporación Autónoma Regional del Cauca, 2009)

El cambio de vocación productiva no solo induce la modificación del territorio, sino las formas sociales y las economías regionales tradicionales en las que el trueque da paso a una economía de mercado, en donde ya hay que comprar lo que antes producían.

Figura 6. La minería en Cauca

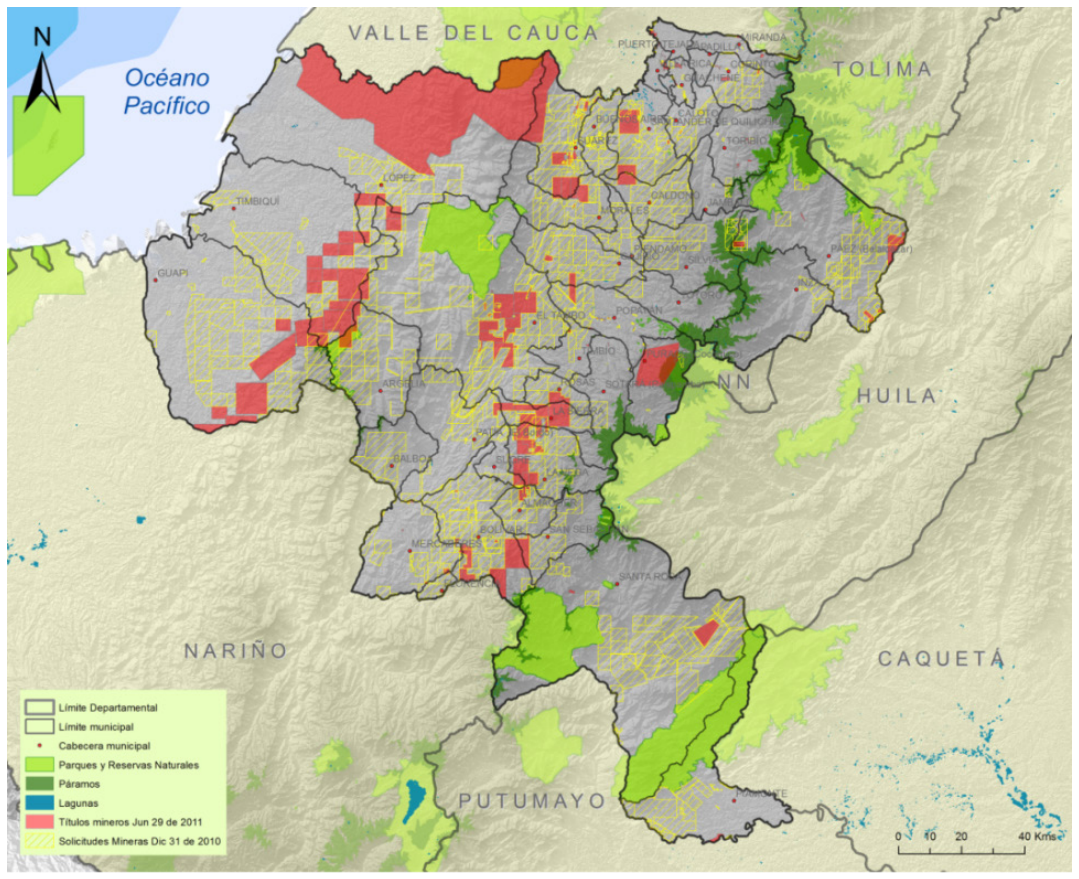

Fuente: Comunidades Interactivas.

La minería es la que mayores impactos produce por la naturaleza de dicha actividad y la extensión que presenta en el Cauca. En el departamento existen comunidades de mineros afrodescendientes que 
remontan sus orígenes a la época colonial y que han explotado dichos recursos a pequeña escala y sin daño para el medioambiente. Hoy en día esta actividad se plantea a gran escala mediante concesiones mineras a compañías multinacionales o a empresarios locales y regionales. Es así como el Estado ha definido los espacios con potencial explotación minera, que han experimentado una extraordinaria ampliación a partir de la ley 1450 de 2011, la cual incluye las áreas de reserva estratégica del Estado. Está ley no excluyó entre otros espacios las zonas de reserva forestal de la ley 2 de 1959, ni las áreas de reserva forestal regionales, ni tampoco las zonas de utilidad pública declaradas por el gobierno nacional, al considerar que la minería podría llevarse a cabo en la medida en que se realicen los trámites administrativos correspondientes. Y aunque se evitaron áreas relevantes conforme a la ley 685 de 2001, una buena parte de bloques mineros se superponen sobre zonas de especial importancia ecológica que ven comprometida su vocación de conservación.

En el mapa de las áreas estratégicas mineras son visibles estos bloques en Amazonía, sobre Reservas de la Biosfera o en cinturón andino (figura 6). Pero además se superponen sobre territorios habitados ancestralmente por comunidades étnicas y campesinas, sin que se haya tenido en cuenta su autodeterminación o las actividades que actualmente realiza la población de esos territorios. De hecho, en las nuevas explotaciones mineras, primero entran los aserradores que limpian la zona con sus mulas de árboles maderables, después se incorporan las retroexcavadoras, y -desplazados los campesinos y destruidos sus cultivos tradicionales- se plantan los cultivos de coca controlados por los grupos armados (González Perafán, 2013). Además, de forma incomprensible, para adelantar la etapa de exploración de proyectos mineros no se requiere solicitar licencia ambiental, únicamente se tramitan los permisos ambientales ante la corporación ambiental que opere en la zona del proyecto. Asimismo las autoridades locales no cuentan con autoridad suficiente para imponer sanciones o impedir actuaciones en las zonas donde se está explotando el mineral ilegalmente.

Los impactos medioambientales derivados (Contraloría General de la República, 2014) son gravísimos. Destaquemos:

- La contaminación del suelo con grasas y aceites, lodos de perforación y aguas residuales que aumentan los sedimentos y generan residuos sólidos peligrosos en extensas áreas de bosques o en los cauces de los ríos.

- La utilización indiscriminada de mercurio o cianuro ocasiona graves enfermedades a las comunidades, compromete la fauna de la región y contamina los acuíferos.

- El desmonte de los relieves para hacer llegar las retroexcavadora hasta los lugares más inaccesibles altera la red hidrográfica: modifica los cauces de los ríos, aumenta o disminuye su caudal, afecta a la oxigenación, con la pérdida de sus calidades fisicoquímicas y resultan eventuales desastres naturales por fenómenos climatológicos. Además se comprometen las necesidades de abastecimiento de las poblaciones asentadas, aniquilando incluso la pesca fluvial, recurso indispensable en las economías y dieta campesina.

Asimismo los impactos medioambientales, desde un punto de vista social, son profundos pues, además de generar graves enfrentamientos sociales, las mujeres barequeras de las comunidades afrocolombianas han sido despojadas de sus medios de vida y han perdido su autonomía, en donde por tradición representan el eje de autoridad sobre el cual gira la vida familiar. Igualmente la instalación de campamentos, plataformas y otras infraestructuras asociadas ocasionan problemas de convivencia entre campesinos nativos y foráneos. En definitiva la llegada de la minería está produciendo el rompimiento del tejido social, de los lazos familiares, de los procesos organizativos, la desintegración de las comunidades tradicionales.

Con todo, el gobierno sigue otorgando títulos a particulares en las zonas donde existen consejos comunitarios, sin la debida consulta previa, ni el consentimiento de las comunidades y falta un control ambiental, social o militar por su parte. Además se da la contradicción de que el Estado no reconoce la minería tradicional, sino que por el contrario, la asimila a la minería ilegal y genera estigmatización sobre las comunidades que la practican (González Perafán, 2013). 


\section{CONCLUSIONES}

No se puede perder de vista que la tierra y los territorios por su valor estratégico en el conflicto, por su valor económico y el de los recursos naturales que albergan son el elemento clave para la perpetración de un conflicto violento, propiciado por el interés de agentes externos, grupos armados y actores económicos que despojan a los pueblos indígenas y campesinos de sus territorios ancestrales, forzándolos al desplazamiento (Comisión Interamericana de Derechos Humanos, 2013).

A la vista de los hechos analizados y de los acontecimientos más recientes, la situación de los desplazados en Cauca es que se encuentran lejos de un posible retorno, que difícilmente han mejorado su situación o que puedan hacerlo en el actual escenario real de posconflicto. Ello se debe, en buena parte, a que el Estado sigue entendiendo los desplazamientos como un efecto de la lucha de grupos armados, y que difícilmente puede actuar ante la magnitud de dicho fenómeno. Dicha concepción explica que los gobiernos hayan esbozado respuestas meramente asistencialistas sin incidir de manera tajante sobre las causas y los causantes de los desplazamientos humanos. Situación de fondo que está alargando y que hace peligrar los procesos de paz encaminados al restablecimiento de una paz duradera. Por otro lado la política de Seguridad Democrática, basada en el fortalecimiento de la inversión militar y la presencia del ejército en los territorios estratégicos, está lastrando las demandas de inversiones sociales y agudizando la desigualdad, ya que faltan políticas que piensen en términos de desarrollo agrario social o de intervención en los asuntos macroeconómicos y de control de los agentes económicos externos (Bello y Villa, 2005).

Para subsanar el desplazamiento forzado es necesario actuar sobre aquellas circunstancias que obligaron a los campesinos a abandonar sus tierras. Los municipios no alcanzan a atender a los cientos de personas que diariamente engrosan los cinturones de pobreza de Popayán y de las cabeceras municipales, y reubicarlos no es solución para reintegrar a unas comunidades desarraigadas por la violencia. El Sistema Nacional de Atención a la Población Desplazada (SNAPD) y la Red de Solidaridad Social (RSS) no alcanzan a solucionar tampoco el problema pues no llegan al reconocimiento de toda la población desplazada. Por su parte la Unidad de Restitución de Tierras, que fue creada en base a la ley 1448 de 2011 y que pretende establecer un procedimiento legal para restituir la tierra a las víctimas del despojo y abandono forzoso, está encontrando unas dificultades y resistencias extraordinarias que impiden una avance significativo en el retorno de las poblaciones desplazadas.

El CRIC también procura retornar a los indígenas a sus resguardos, mientras que los afrodescendientes recurren a las redes familiares y a la reconstrucción de su parentesco por vía materna. Además en Cauca interactúan hasta 196 organizaciones nacionales e internacionales (OCHA-Sidih, 2014) que ayudan a visibilizar el conflicto y a paliar sus consecuencias, pero que -en la mayoría de los casos- trabajan de forma inconexa o reducen sus proyectos al establecimiento de planes de generación productiva que dejan de funcionar cuando se agotan las inyecciones de capital. Hasta los grupos armados han sido reconocidos como actores políticos y sujetos potenciales en los procesos de negociación actuales, de manera que se hacen responsables, hasta cierto punto, de la trayectoria de la población desplazada.

Pero a esta población desplazada no se le permite actuar ni empoderarse como protagonista político y social en la solución de sus propios problemas. Es más se le niega incluso el derecho a la justicia, que debe comenzar por el esclarecimiento de lo sucedido y el juicio a los culpables, deberes estos de los que el Estado se tiene que hacer subsidiario, como expresa la controvertida Ley de Justicia y Paz (Ley 975 de 2005) y que amplia otro conjunto de medidas judiciales y políticas denominadas Justicia Transicional. Medidas que no alcanzan a reparar las violaciones masivas de derechos humanos y que deben comprender la restitución de las tierras, la compensación por los daños irreparables físicos o materiales, la garantía de no repetición, el público reconocimiento de los hechos sucedidos y sanciones para los victimarios ${ }^{7}$.

La resolución del conflicto del desplazamiento humano en Colombia pasará necesariamente por el Cauca y la firma de los Acuerdos de Paz que se promueven actualmente en La Habana, acuerdos que si no conllevan una hoja de ruta donde se contemple, además del cese del enfrentamiento armado, la superación de las causas que lo originaron y la reparación integral a la población desplazada, podrían llevar al cierre en falso del conflicto. Igualmente es preciso contemplar el ejemplo caucano como un escenario antológico desde la perspectiva de la prevención de las causas de los desplazamientos, desde la conside-

7 En este sentido el Centro Internacional para la Justicia Transicional (ICTJ) acoge el anuncio del acuerdo entre el gobierno de Colombia y las FARC de crear una Comisión de la Verdad una vez firmado un acuerdo definitivo de paz. Junio 2015. 
ración del territorio como soporte de los modos de vida de las comunidades ancestrales y desde la restitución de los derechos y reparación a la población desplazada.

Recientemente, el 15 de diciembre de 2015, la firma en La Habana de un nuevo acuerdo ha supuesto un importante paso adelante: en el mismo, las víctimas del conflicto no solo se ponen en el centro del proceso de paz -y nunca antes las víctimas habían estado en el centro de un proceso de paz en Colombia ${ }^{8}$; sino que además, se inicia una hoja de ruta, un proyecto consensuado de verdad, justicia y reparación. Las cinco estrategias claves acordadas para reparar a las víctimas serían: La creación de una Comisión para Esclarecimiento de Verdad, Convivencia y No Repetición, una Unidad Especial para búsqueda de desaparecidos en el marco del conflicto, una Jurisdicción especial para la paz, diferentes Medidas de reparación integral para la construcción de la paz y Garantías de no repetición. ${ }^{9}$

En definitiva, se requiere también -como propone Ulloa (2012)- repensar los enfoques convencionales para el análisis de los territorios indígenas, y plantear otras maneras de entender la autonomía territorial y el control de los territorios. Las dinámicas espaciales y demográficas deben estar presididas por el concepto de autonomía relacional indígena que a su vez reconozca alternativas de control territorial y que finalmente posicione los territorios indígenas en los contextos nacionales y globales.

\section{REFERENCIAS}

Alto Comisionado de las Naciones Unidas para los Refugiados [ACNUR] (2009). Violencia de género y mujeres desplazadas.

Bello, M. N. (2004). El desplazamiento forzado en Colombia: Acumulación de capital y exclusión social. En M. M. Bello (Ed.), Desplazamiento forzado. Dinámicas de guerra, exclusión y desarraigo (pp. 19-30). Bogotá: Universidad Nacional de Colombia.

Bello, M. N. y Peña, N. (2000). Migración y desplazamiento forzado: de la exclusión a la desintegración de las comunidades indígenas, afrocolombianas y campesinas. Bogotá: Universidad Nacional de Colombia.

Bello, M. N. y Villa, M.N. (Comps.). (2005). El desplazamiento en Colombia: Regiones, ciudades y políticas públicas. Medellín: Pregón Ltda.

Castillo de Herrera, M. (Ed.). (2009). Procesos urbanos informales y Territorio. Ensayos en torno a la construcción de sociedad, territorio y ciudad. Bogotá: Universidad Nacional de Colombia.

Coordinadora Andina de Organizaciones Indígenas [CAOI] (2008). Resolución de Pueblos Indígenas sobre el IIRSA. Coordinadora Andina de Organizaciones Indígenas. La Paz, 19 de Enero del 2008.

Consultoría para los Derechos Humanos y el Desplazamiento [CODHES] (2003). Boletín de la Consultoría para los Derechos Humanos y el Desplazamiento, n 44, Bogotá, Colombia, 28 de abril de 2003.

Consultoría para los Derechos Humanos y el Desplazamiento [CODHES] (2013). Desplazamiento forzado intraurbano y soluciones duraderas. Una aproximación desde los casos de Buenaventura, Tumaco y Soacha. Bogotá: Ed. Antropos.

Consultoría para los Derechos Humanos y el Desplazamiento [CODHES] (2014). El desplazamiento humano en Colombia: La huella del conflicto. Recuperado de http://www.codhes.org/images/Articulos/ AnalisisSituacionalfinal.pdf

Comisión Interamericana de Derechos Humanos (2013). Verdad, justicia y reparación: Cuarto informe sobre la situación de derechos humanos en Colombia. OEA CIDH.

Comunidades Interactivas (2012). Cauca Minero. Recuperado de http://www.casadelcauca.org/wpcontent/uploads/2013/04/caucaminerola.png

Conferencia Episcopal de Colombia (1999). Pastoral Social. Boletín RUT Informa, $\mathrm{n}^{\circ}$ 2, abril-junio de 1999.

Contraloría General de la República (2014). Minería en Colombia. Daños ecológicos y socioeconómicos y consideraciones sobre un modelo minero alternativo. Bogotá: Imprenta Nacional de Colombia.

8 En: Radio Francia Internacional (2015). Histórico acuerdo para la reparación a las víctimas del conflicto armado.

9 En: Proclama del Cauca (2015). Se firmó en La Habana Acuerdo sobre las Víctimas del Conflicto. Todos los informes completos aquí. 
Corporación Autónoma Regional del Cauca (2009). Documento de análisis socioambiental del Departamento del Cauca: como elemento para identificación de lineamientos para ajuste de instrumentos de planificación de la CRC. Popayán: CRC.

Declaración de Cartagena sobre los Refugiados (1984). En Coloquio Sobre la Protección Internacional de los Refugiados en América Central, México y Panamá: Problemas Jurídicos y Humanitarios. Cartagena de Indias (Colombia), del 19 al 22 de noviembre de 1984.

Departamento Administrativo Nacional de Estadística [DANE] (2005). Censo General de 2005. Recuperado de http://formularios.dane.gov.co/Anda_4_1/index.php/catalog/109

Departamento Administrativo Nacional de Estadística [DANE] (2007). Proyecciones de población 20052020.

Departamento Administrativo Nacional de Estadística [DANE] (2013). Encuesta agropecuaria Cauca 2012. Bogotá.

Departamento Administrativo Nacional de Estadística [DANE] (2014). Proyecciones de Población. Recuperado de http://www.dane.gov.co/index.php/poblacion-y-demografia/series-de-poblacion

Departamento Administrativo Nacional de Estadística [DANE] (2015). Colombia, importaciones según clasificación CIIU revisión 3. 2000 - 2015 (Marzo). Bogotá.

González Perafán, L. (2013). Impacto de la minería de hecho en Colombia. Estudios de caso: Quibdó, Istmina, Timbiquí, López de Micay, Guapi, El Charco y Santa Bárbara. Bogotá: Instituto de Estudios para el Desarrollo y la Paz.

Guevara Corral, R. D. (2003). La nueva colonización urbana. El desplazamiento urbano. Anuario Americanista Europeo, $\mathrm{n}^{\mathrm{O}}$ 1, 191-205.

Hernández Delgado, E. (2009). Resistencias para la paz en Colombia. Experiencias indígenas, afrodescendientes y campesinas. Revista Paz y Conflictos, $\mathrm{n}^{\circ}$ 2, 117-135.

Instituto Geográfico Agustín Codazzi [IGAC] (2012a). Mapa físico-político departamental. Departamento del Cauca. Recuperado de http://geoportal.igac.gov.co/mapas_de_colombia/igac/mps_fisicos_ deptales/2012/Cauca.pdf

Instituto Geográfico Agustín Codazzi [IGAC] (2012b). Atlas de la Distribución de la Propiedad Rural en Colombia. Bogotá: Imprenta Nacional de Colombia.

Instituto de estudios para el desarrollo y la paz [INDEPAZ] (2013). IX Informe sobre presencia de grupos narcoparamilitares. Bogotá.

Instituto Nacional de Vivienda de Interés Social y Reforma Urbana (1991). Inventario de zonas subnormales: Popayán. Bogotá: Inurbe, Hábitat.

Instituto Nacional Sindical (2005). Megaproyecto y desplazamiento Forzado: una mirada desde la lógica de los Movimientos Sociales. Informe OMAL.

Junta Directiva Regional de Cabildos Indígenas del Cauca (2011). Pronunciamiento de Toribio. Terminar la guerra, defender la autonomía, reconstruir los bienes civiles y construir la paz. Toribío, 20 de julio de 2011.

Ley 387 de 1997 de 18 de julio por la cual se adoptan medidas para la prevención del desplazamiento forzado; la atención, protección, consolidación y esta estabilización socioeconómica de los desplazados internos por la violencia en la República de Colombia, Congreso de Colombia, (1997).

Ley 975 de 2005 de 25 de julio por la cual se dictan disposiciones para la reincorporación de los miembros de grupos armados organizados al margen de la ley, que contribuyan de manera efectiva a la consecución de la paz nacional y se dictan otras disposiciones para acuerdos humanitarios, Congreso de Colombia, (2005).

Machado Cartagena, A. (2013). Esbozo de una memoria institucional. La política de reforma agraria y tierras en Colombia. Bogotá: Centro de Memoria Histórica.

Molano J. (2006). Anglogold Ashanti. La voracidad de las multinacionales de la muerte, el saqueo y la destrucción. En Tribunal Permanente de los Pueblos (TPP). Capitulo Colombia. Sesión Minería. Medellín, Colombia, 10 y 11 de Noviembre de 2006.

Office for the Coordination of Humanitarian Affairs [OCHA]. MONITOR Sala de Situación Humanitaria. Recuperado de http://monitor.colombiassh.org 
Office for the Coordination of Humanitarian Affairs [OCHA]. Sistema de información humanitaria [Sidhi]. Recuperado de http://sidi.umaic.org/sissh/login.php?m_g=consulta

Office for the Coordination of Humanitarian Affairs [OCHA]-Sidih (2014). Colombia Perfil Departamental. Cauca Informe 31 de julio 2014.

Oficina de las Naciones Unidas contra la Droga y el Delito [UNODC] (2014). Colombia. Monitoreo de Cultivos de Coca 2013. Bogotá: Oficina de la Naciones Unidas contra la Droga y el Delito.

Oficina del Alto Comisionado de las Naciones Unidas para los Derechos Humanos [OACNUDH], United Nations High Commissioner for Human Rights [UNHCHR] (2012). Informe anual de la Alta Comisionada de las Naciones Unidas para los Derechos Humanos sobre la situación de Derechos Humanos en Colombia durante el año 2011. Naciones Unidas.

Oficina del Alto Comisionado de las Naciones Unidas para los Derechos Humanos [OACNUDH], United Nations High Commissioner for Human Rights [UNHCHR] (2013). Informe anual de la Alta Comisionada de las Naciones Unidas para los Derechos Humanos sobre la situación de Derechos Humanos en Colombia durante el año 2012. Naciones Unidas.

Osorio Pérez, F. E. (2001). Actores y elementos en la construcción de una nueva categoría social en Colombia: los desplazados. Scripta Nova. Revista Electrónica de Geografía y Ciencias Sociales, 94 (1). Recuperado de http://www.ub.edu/geocrit/sn-94-38.htm

Programa de las Naciones Unidas para el Desarrollo [PNUD] (2011). Colombia Rural. Razones para la esperanza. Informe Nacional de Desarrollo Humano 2011. Bogotá: INDH PNUD.

Proclama del Cauca (2015). Se firmó en La Habana Acuerdo sobre las Víctimas del Conflicto. Todos los informes completos aquí. Recuperado de http://www.proclamadelcauca.com/2015/12/72292.html

Radio Francia Internacional (2015). Histórico acuerdo para la reparación a las víctimas del conflicto armado. Recuperado de http://es.rfi.fr/americas/20151215-colombia-farc-victimasacuerdo-paz-habana-callemarquez-santos

Rojas J. y Romero M. (2000). Conflicto armado y desplazamiento forzado interno en Colombia, En CODHES-UNICEF. Esta guerra no es nuestra. Niños y desplazamiento forzado en Colombia (pp. 4-34). Bogotá: Gente Nueva.

Salas Salazar, L. G. (2010). Corredores y territorios estratégicos del conflicto armado colombiano. Una prioridad por territorializar en la geopolítica de los actores armados. Perspectiva Geográfica: Revista del Programa de Estudios de Posgrado en Geografía, vol. 15, (1), 9-36.

Secretaria General de la Comunidad Andina (2009). Cosmovisión del pueblo indígena Nasa en Colombia: Reducción integral de los riesgos, planificación y desarrollo sostenible. Lima: Pull Creativo SRL.

Ulloa, A. (2012). Los territorios indígenas en Colombia: de escenarios de apropiación transnacional a territorialidades alternativas, Scripta Nova. Revista Electrónica de Geografía y Ciencias Sociales, vol. XVI, (418). Recuperado de http://www.ub.edu/geocrit/sn/sn-418/sn-418-65.htm

Universidad Santo Tomás [USTA] y Office for the Coordination of Humanitarian Affairs [OCHA] (2009). Índice de Riesgo de Situación Humanitaria. Bogotá.

Universidad Santo Tomás [USTA] y Office for the Coordination of Humanitarian Affairs [OCHA] (2010). Índice de Riesgo de Situación Humanitaria. Recuperado de https://www.humanitarianresponse.info/ sites/www.humanitarianresponse.info/files/120124_IRSHIISem10_1_.pdf

Valderrama, M. y Mondragón H. (1998). Desarrollo y equidad con campesinos. Bogotá: TM Editores.

Vélez Torres, I., Rátiva Gaona, S. y Varela Corredor, D. (2012). Cartografía social como metodología participativa y colaborativa de investigación en el territorio afrodescendiente de la cuenca alta del río Cauca. Cuadernos de Geografía. Revista Colombiana de Geografía, vol. 21, (2), 59-73. Recuperado de http://www.revistas.unal.edu.co/index.php/rcg/article/view/25774

Zuluaga, J. (2004). La guerra interna y el desplazamiento forzado. En ACNUR. Desplazamiento forzado: Dinámicas de guerra, exclusión y desarraigo (pp. 31-47). Bogotá: Universidad Nacional de Colombia. 